\title{
APPLICATION OF CRYPTOGRAPHY WITH DATA ENCRYPTION STANDARD (DES) ALGORITHM IN PICTURE
}

\author{
Angga Aditya Permana ${ }^{1}$, Desi Nurnaningsih ${ }^{2}$ \\ 1,2 Program Studi Teknik Informatika, Fakultas Teknik, Universitas Muhammadiyah Tangerang \\ Jalan Perintis Kemerdekaan 1/33 Cikokol Kota Tangerang \\ email : anggaumt@gmail.com ${ }^{1}$, desi.nurnaningsih1986@gmail.com ${ }^{2}$
}

\author{
Article history \\ Received May 18, 2020 \\ Revised May 19, 2019 \\ Accepted May 27, 2019 \\ Available online May 31, 2020 \\ Keywords \\ Cryptograph \\ Algorithm \\ Date Encryption Standard
}

\begin{abstract}
Cryptography is the science of maintaining data confidentiality, where the original text (plaintext) is encrypted using an encryption key to be ciphertext (text that has been encrypted). In this case cryptography secures data from a third party so that the third party cannot know the original contents of the data because the one who holds the key for encryption and decryption is only the sender and receiver. There are several cryptographic methods that are commonly used, one of which is DES or Data Encryption Standard. DES is included in the key-symmetric cryptography and is classified as a block cipher type.
\end{abstract}

\begin{abstract}
Abstrak
Kriptografi adalah ilmu untuk menjaga kerahasiaan data, dimana teks asli (plaintext) diacak menggunakan suatu kunci enkripsi menjadi ciphertext (teks yang sudah terenksipsi). Dalam hal ini kriptografi mengamankan data dari pihak ketiga agar pihak ketiga tersebut tidak dapat mengetahui isi asli dari data tersebut karena yang memegang kunci untuk enkripsi dan dekripsi hanya pengirim dan penerima. Terdapat beberapa metode kriptografi yang umum digunakan, salah satunya adalah DES atau Data Encryption Standard. DES termasuk ke dalam kriptografi kunci-simetris dan tergolong jenis block cipher.
\end{abstract}

\section{PENDAHULUAN}

Teknologi pada masa kini sudah mengalami perkembangan yang sangat pesat. Teknologi khususnya dalam bidang komunikasi telah memudahkan kita dalam berkomunikasi hanya lewat telepon genggam atau hp kita. Di sosial media kita dapat mengirimkan tidak hanya teks kita juga berbagai macam hal lain contohnya seperti audio, gambar, dan video.

Seiring dengan perkembangan teknologi komunikasi, keamanan dan kerahasiaan data dalam berkomunikasi menjadi hal yang krusial dan patut diperhatikan. Karena data yang akan dikirimkan adalah hal yang sangat berharga, keamaan dibutuhkan agar segala data yang dikirimkan tidak dapat dilihat, diubah, maupun dihapus oleh orang ketiga yang tidak mempunyai hak untuk melakukannya. Teknik dalam mengamankan data dapat dilakukan dengan berbagai macam hal, salah satunya adalah dengan menggunakan teknik kriptografi.

Permana (2018) telah melaporkan metode kriptografi yang diaplikasikan untuk pengamanan teks dengan algoritma vigenere chiper menggunakan perangkat android. Permana dan Nurnaningsih (2018) juga melaporkan metode kriptografi yang digunakan untuk merancang aplikasi pengamanan teks menggunakan algoritma Advanced Encyption Standard (AES). Kedua jurnal tersebut melaporkan pengamanan data dalam bentuk teks, sehingga pengamanan data dalam bentuk gambar perlu dianalisis lebih lanjut. Pada penelitian ini data yang diamankan berupa gambar, dengan teknik kriptografi menggunakan algoritma Data Encryption Standard (DES). Algoritma DES adalah salah satu metode 
penyandian dengan sistem block cipher. Yaitu sistem penyandian yang pengacakannya dilakukan secara blok demi blok dengan blok input (teks asli) 64 bit dan menghasilkan output (teks sandi) yang juga per blok 64 bit, algoritma yang digunakan adalah kunci simetris dengan panjang kunci 56 bit.

\section{Kriptografi}

\section{KAJIAN LITERATUR}

Kriptografi adalah ilmu dan teknik dalam pengamanan data dari pihak ketiga. Pada kriptografi terdapat istilah enkripsi dan dekripsi. Enkripsi adalah mengubah text awal (plain text) menjadi text ter-enkripsi (cipher text) menggunakan sebuah kunci. Sedangkan Dekripsi adalah mengubah text ter-enkripsi (cipher text) kembali menjadi text awal (plain text) dengan menggunakan kunci yang sama, dalam hal ini jika menggunakan symmetric-key cryptography. Permana (2017)

\section{Tipe Kriptografi}

Terdapat tiga macam kriptografi:

- Kriptografi Kunci Simetris (Symmetric Key Cryptography):

Kriptografi ini menggunakan kunci yang sama untuk enkripsi dan dekripsi pesan. di mana pengirim dan penerima pesan menggunakan kunci yang sama untuk enkripsi dan dekripsi pesan. Ada beberapa macam algoritma yang termasuk ke dalam symmetric-key cryptography, salah satu algoritma yang paling terkenal dari Kriptografi kunci simetris ini adalah DES (Data Encryption Standard).

- Kriptografi Kunci Asimetris (Asymmetric Key Cryptography):

Kriptografi ini menggunakan sepasang kunci yang berbeda untuk enkripsi dan dekripsinya. Sebuah kunci publik (public key) digunakan untuk enkripsi dan kunci rahasia (private key) digunakan untuk dekripsi. Public key dan Private Key adalah hal yang berbeda. Walaupun jika kunci publik diketahui oleh semua orang, hanya penerima lah yang dapat men-decrypt informasi tersebut karena hanya dia yang tahu kunci rahasia (private key) nya.
- Kriptografi Hybrid

Kriptografi ini memadukan symmetric dan asymmetric cipher

Dalam penggunaannya. Pengirim mengenkripsi pesan dengan session key, lalu session key tersebut di-encrypt kembali dengan menggunakan public key. Lalu, penerima men-decrypt session key tersebut dengan priate key yang dimilikinya.

\section{METODE}

\section{Data Encryption Standard (DES)}

Data Encryption Standard (DES) termasuk ke dalam algoritma kunci-simetris, dimana kunci yang sama digunakan untuk enkripsi dan dekripsi. DES termasuk ke dalam blok cipher, dimana data tergabung dalam blok berukuran masing-masing 64 bit. DES mengenkripsikan 64 bit plainteks menjadi 64 bit cipherteks dengan menggunakan 56 bit kunci internal (internal key) atau sub-kunci (subkey). Kunci internal dibangkitkan dari kunci eksternal (external key) yang panjangnya 64 bit. Skema global dari algoritma DES adalah sebagai berikut:

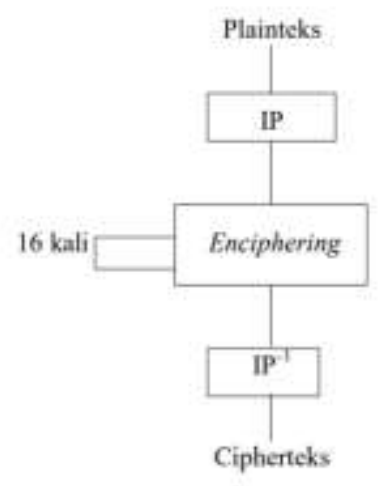

Gambar 1. Skema Global Algoritma DES (Munir, 2004)

\section{Skema Global Dari Algoritma DES adalah sebagai berikut:}

- Blok plaintext dipermutasi dengan matriks permutasi awal (Initial Permutation atau IP).

- Hasil permutasi awal kemudian dienchipering sebanyak 16 kali putaran. Setiap putaran menggunakan kunci internal yang berbeda. 
- Hasil enchipering kemudian dipermutasi dengan matriks permutasi balikan (invers initial permutation atau $\mathrm{IP}^{-1}$ ) menjadi blok ciphertext.

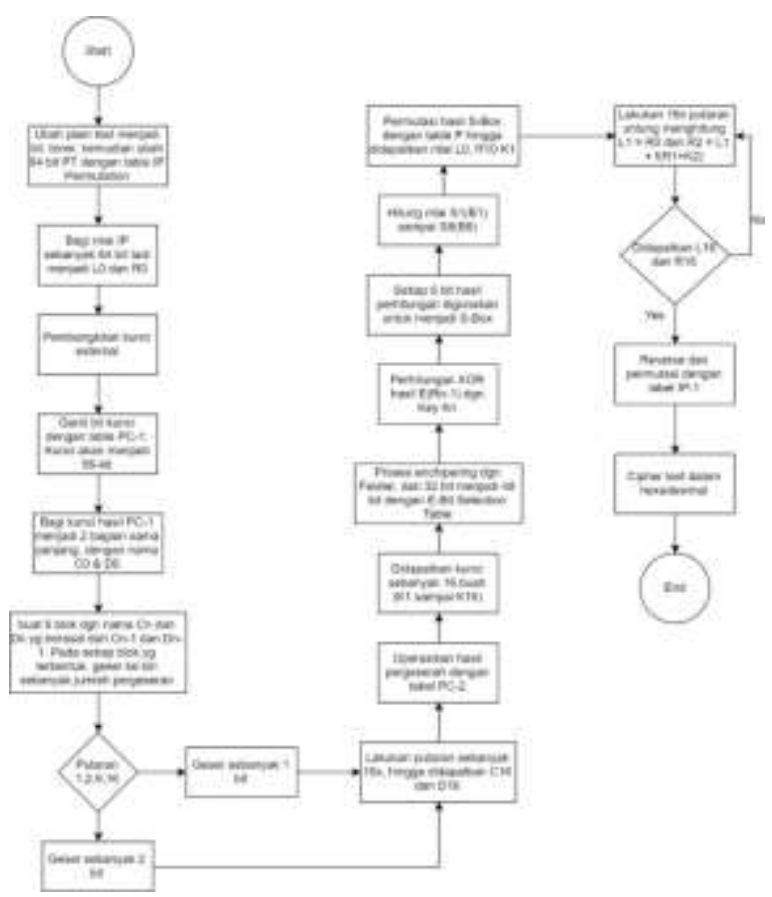

Gambar 2. Flowchart Algoritma DES

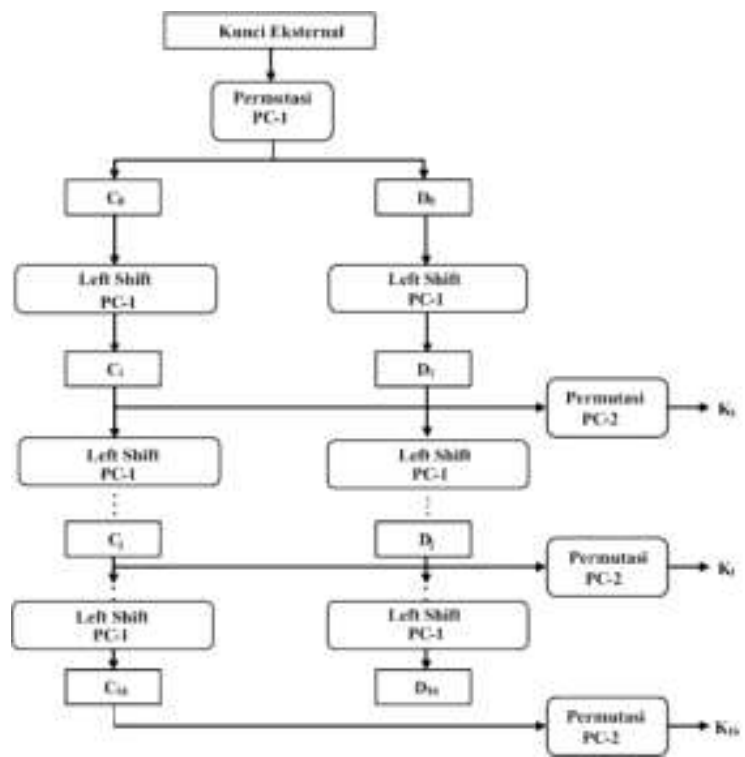

Gambar 3 Proses Pembangkitan Kunci (Munir, 2004)

\section{Hasil dan Pembahasan \\ Perancangan Aplikasi \\ Aplikasi enkripsi dengan algoritma DES ini dibuat dengan menggunakan Bahasa pemrograman Java. Panjang key yang di- inputkan harusnya 8 byte ( 8 karakter).}

\section{User Interface}

Berikut ini adalah tampilan aplikasi yang dibuat dengan menggunakan Netbeans IDE.

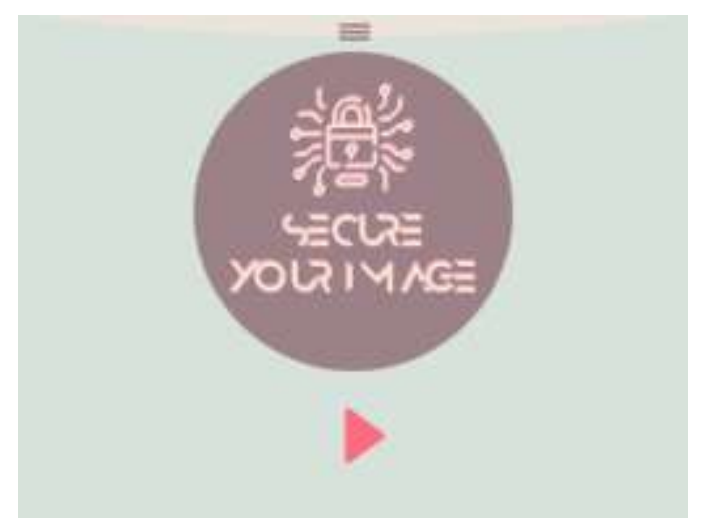

Gambar 4. Menu awal; Button start

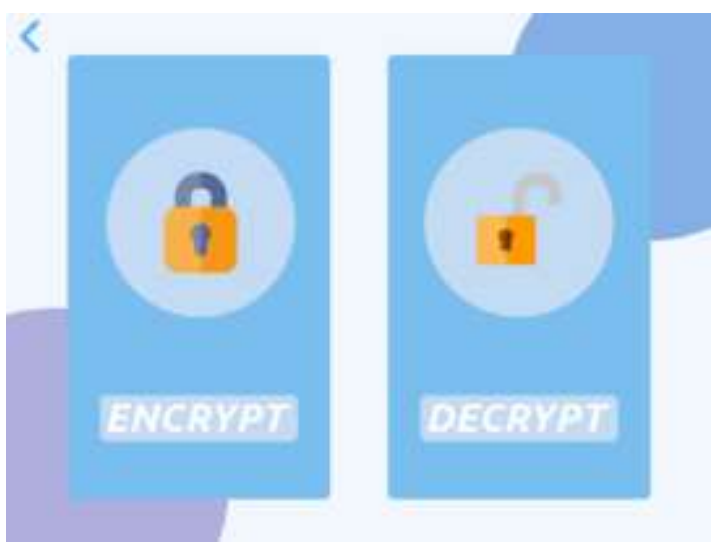

Gambar 5. Menu Utama 


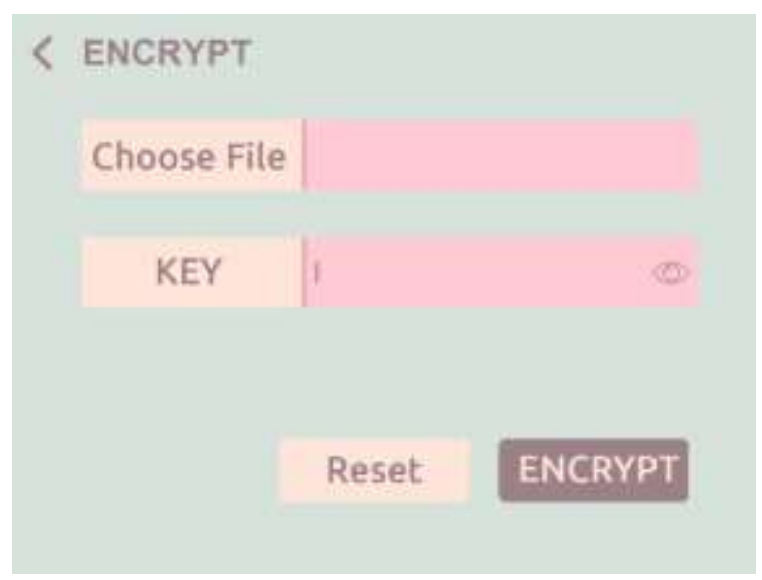

\section{Gambar 6. Menu Encrypt}

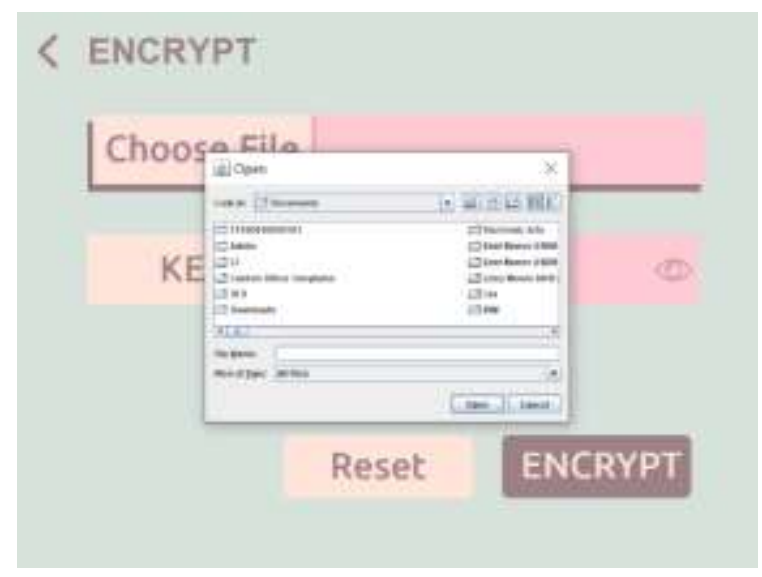

Gambar 7. Choose File / File Destination

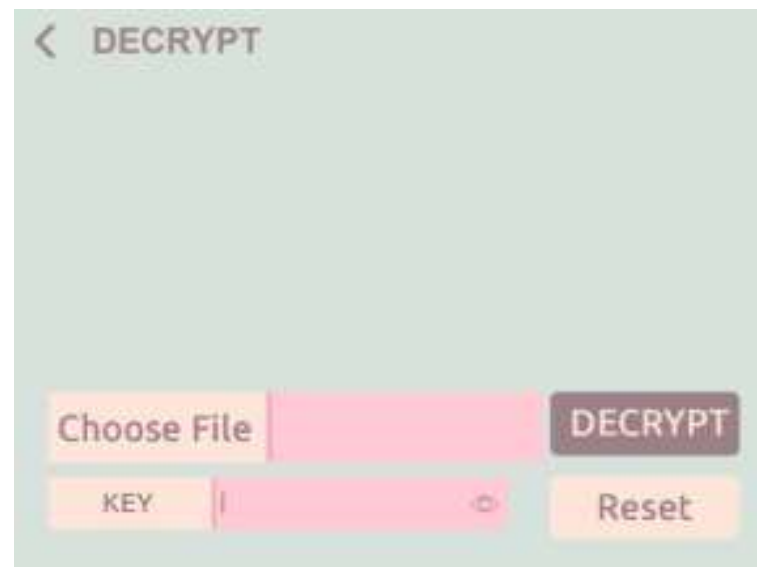

Gambar 8. Menu Decrypt

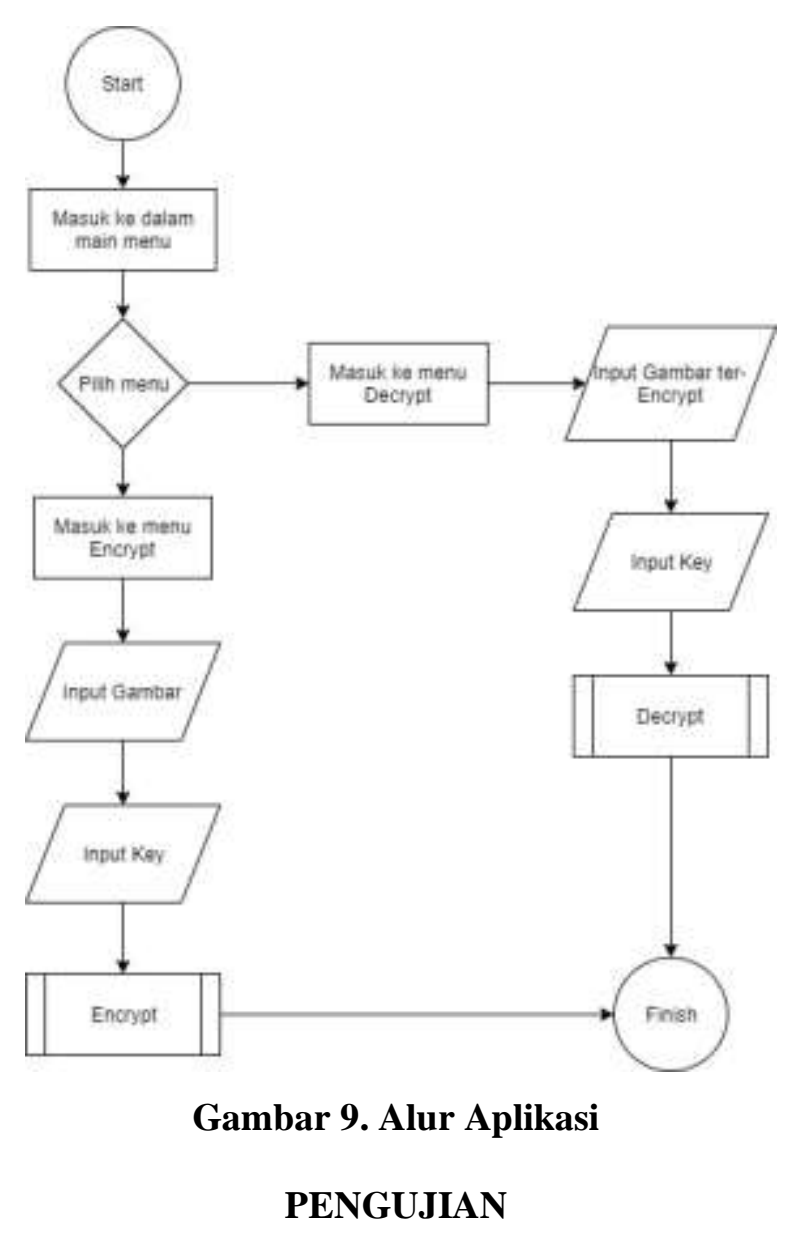

Tabel 1. BlackBox Testing Aplikasi

\begin{tabular}{|c|c|c|c|}
\hline No & $\begin{array}{l}\text { Pengujian } \\
\text { Skenario }\end{array}$ & $\begin{array}{l}\text { Hasil yang } \\
\text { diharapka } \\
\text { n }\end{array}$ & $\begin{array}{l}\text { Kesimpula } \\
\text { n }\end{array}$ \\
\hline 1 & $\begin{array}{l}\text { Mengosongkan } \\
\text { field pilihan } \\
\text { gambar dan } \\
\text { key, lalu klik } \\
\text { tombol } \\
\text { "Encrypt" } \\
\end{array}$ & $\begin{array}{l}\text { Sistem } \\
\text { akan } \\
\text { menolak } \\
\text { proses } \\
\text { Encrypt } \\
\text { dan } \\
\text { mengeluark } \\
\text { an pop up } \\
\text { dialogue } \\
\text { file not } \\
\text { found }\end{array}$ & Valid \\
\hline 2 & $\begin{array}{l}\text { Mengosongkan } \\
\text { key setelah }\end{array}$ & $\begin{array}{l}\text { Sistem } \\
\text { menolak }\end{array}$ & Valid \\
\hline
\end{tabular}




\begin{tabular}{|c|c|c|c|}
\hline & $\begin{array}{l}\text { memilih } \\
\text { gambar yang } \\
\text { akan di- } \\
\text { encrypt, lalu } \\
\text { klik button } \\
\text { "Encrypt" }\end{array}$ & $\begin{array}{l}\text { proses } \\
\text { encrypt dan } \\
\text { muncul pop } \\
\text { up dialogue } \\
\text { EmptyKey }\end{array}$ & \\
\hline 3 & $\begin{array}{l}\text { Field gambar } \\
\text { terisi } \\
\text { panjang } \\
\text { tidak key } \\
\text { dengan } 8 \text { byte, } \\
\text { lalu klik button } \\
\text { "Encrypt" } \\
\end{array}$ & $\begin{array}{l}\text { Sistem } \\
\text { menolak } \\
\text { proses } \\
\text { encrypt dan } \\
\text { muncul pop } \\
\text { up dialogue } \\
\text { Wrong Key } \\
\text { Size }\end{array}$ & Valid \\
\hline 4 & 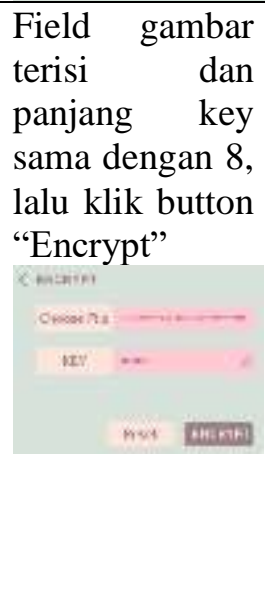 & $\begin{array}{l}\text { Sistem } \\
\text { berhasil } \\
\text { mengenkrip } \\
\text { si gambar } \\
\text { dan muncul } \\
\text { pop up } \\
\text { dialogue } \\
\text { The file } \\
\text { encrypted } \\
\text { successfull } \\
\text { y } \\
\end{array}$ & Valid \\
\hline 5 & $\begin{array}{l}\text { Mengosongkan } \\
\text { field pilihan } \\
\text { gambar dan } \\
\text { key, lalu klik } \\
\text { tombol } \\
\text { "Decrypt" }\end{array}$ & $\begin{array}{l}\text { Sistem } \\
\text { menolak } \\
\text { proses } \\
\text { Decrypt } \\
\text { dan muncul } \\
\text { pop up } \\
\text { dialogue } \\
\text { File not } \\
\text { found }\end{array}$ & Valid \\
\hline 6 & $\begin{array}{l}\text { Field gambar } \\
\text { terisi, namun } \\
\text { key salah }\end{array}$ & $\begin{array}{l}\text { Sistem } \\
\text { menolak } \\
\text { proses }\end{array}$ & Valid \\
\hline
\end{tabular}

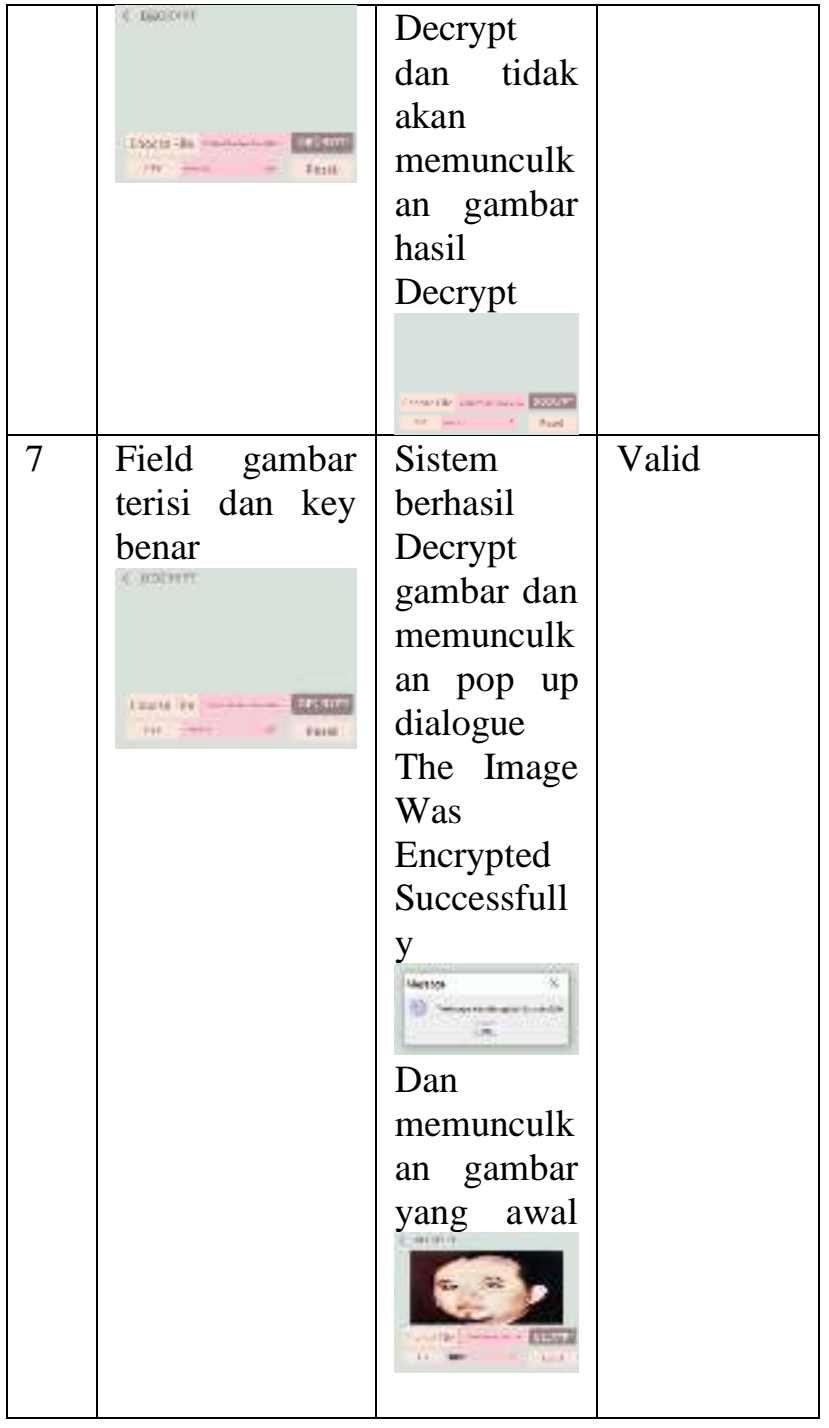

\section{KESIMPULAN}

Berdasarkan aplikasi yang telah dirancang menggunakan Algoritma DES dengan input berupa gambar, dapat berhasil mengenkripsi gambar tersebut. Panjang kunci untuk Algoritma DES harus sepanjang 8 byte atau 8 karakter, karena DES adalah algoritma kriptografi blokchiper 64 bit. Sedangka kunci yang digunakan untuk men-decrypt adalah kunci yang sama dengan kunci saat meng-encrypt.

Kelemahan dari algoritma DES sendiri adalah, ketika gambar yang terencrypt dan dibuka maka akan bertuliskan Image not supported, yang akan menimbulkan kecurigaan pada pihak ketiga. Selain itu karena kunci yang digunakan sama, kunci dapat mengalami kebocoran. 


\section{DAFTAR PUSTAKA}

Data Encryption Standard (DES), diakses pada 5 Januari $2020 \quad$ Website : http://informatika.stei.itb.ac.id/ rinaldi.mu nir/Kriptografi/Data\%20Encryption\%20St andard\%20(DES).pdf

Firmansyah, R dan Permana, A, A,. 2019, Implementasi Keamanan Pesan Teks Menggunakan Kriptografi Algoritma RSA dengan Metode Waterfall berbasis JAVA, Joutica Vol 4 No 1, ISSN : 2621-511X.

Munir, R. (2004). Bahan Kuliah IF5054 Kriptografi. Departemen Teknik Informatika, Institut Teknologi Bandung.

Permana, A, A,. 2017, Aplikasi Penyisipan Teks Pada Gambar dengan Algoritma Blowfish dan Least Significant Bit, JIKA (Jurnal Informatika) Vol 1 No 1, ISSN : 25490710 .

Permana, A, A. 2018. Penerapan Kriptografi Pada Teks Pesan dengan Menggunakan Metode Vigenere Cipher Berbasis Android. Jurnal Al-Azhar Indonesia Seri Sains dan Teknologi, Vol 4 No 3, ISSN : 2355-8059.

Permana, A, A. Nurnaningsih, D. 2018. Rancangan Aplikasi Pengamanan Data Dengan Algoritma Advanced Encryption Standard (AES). Jurnal Teknik Informatika Vol 11 No. 2, ISSN : 25497901.

Primartha, R,. 2011, Penerapan Enkripsi Dan Dekripsi File Menggunakan Algoritma Data Encryption Standard (DES), Jurnal Sistem Informasi Unsri, ISSN : 23554614. 